\title{
Barriers to Effective Prevocational education implementation in Jordanian Schools as Perceived by Teachers
}

\author{
Tariq Yousef Jawarneh \\ Yarmouk University Irbid, Jordan \\ tjawarneh@yu.edu.jo
}

\begin{abstract}
The main goal of this qualitative study was to explore perceptions and opinions of a group of in-service Prevocational Education (PVE) teachers to derive barriers to effective PVE implementation at the middle basic stage in Jordanian schools. The population and sample $(n=35$ of the study consisted of all teachers responsible for the delivery of PVE at the middle basic stage of the "North Mazar" educational directorate in the northern region in Jordan. The population and sample of the study were conveniently selected. The instrument used in this study was an interview schedule and technique used in analyzing data obtained from open-ended face-to-face interviews was that suggested by Merriam (2009) regarding qualitative data. Frequencies, percentages in addition to examples of sample quotes representing teachers' responses were provided. The results revealed that PVE lack attractiveness for pupils, parents, teachers, and principals and consequently they hold negative attitudes towards this practical provision. The results revealed four categories of barriers: (1), Barriers pertaining to perceptions and attitudes (2) barriers pertaining to economic factors, (3) barriers pertaining to administrative factors, (4) Barriers pertaining to human factors. Discussions of such barriers were provided, and concluding reflections and recommendations were presented.
\end{abstract}

Keywords: Prevocational Education, Technology Education, Middle School, Teachers' Perceptions

\section{Introduction}

The education system in Jordan consists of three main components: basic education (Lower, middle and upper stage, age 6 16; 10 years), which is compulsory; secondary education (age 16-18, 2 years); and higher education (colleges and universities, age 18+, 2 \&4 years). The Jordanian Education system is centralized. All schools throughout the country must use the same curricula, which are developed and implemented by the Ministry of Education. The introduction of PVE at the middle basic stage of schooling in Jordan is intended to achieve a variety of general objectives, such as: inculcating in students positive attitudes towards manual work and workers, enabling students to acquire practical and applicable skills with economic and social benefits, enable young people to make better informed choices about their future through hands-on experiences. In addition, PVE aims at acquainting students with the practical application of knowledge obtained from other subjects, improving students' creativity and problemsolving, providing students with basic technological literacy for everyday living, raising students awareness of domestic life requirements, improving their "sense of responsibility" towards the environment, and enabling them to communicate through drawings and symbols (MoE, 1990). The recommendations emanated from the first national conference for educational reform convened in Amman in 1987 argued that courses in PVE at the primary level should play a prominent role as part of the primary curriculum (MoE, 1988). PVE curriculum at this stage consists of modularized training packages in agriculture; industry; business; home economics and health and safety (MoE, 1993). At this stage, which is termed as the career orientation stage, aims to enable students to explore available careers through manual skill and hands-on experiences (Ulaimat, 1991; Hendrix, 1986; MoE, 1993). The curriculum at this stage is, therefore, not vocational in the conventional sense. The curriculum is delivered through a teacher's guide and students' workbooks. From the context of this subject and experiences students are expected to acquire and be exposed to a vast array of content possibilities. The curriculum guidelines state that PVE is delivered at the middle basic stage by a PVE teacher specifically prepared to teach PVE.

The implementation of PVE involves a variety of activities that require different skills and competencies. Teachers who actually implement the curriculum of ought to be well prepared. However, the debate and concerns of PVE teachers' inability to teach PVE and issues surrounding the resources required to teach 
the subject in addition to the attitudes and perceptions of all stakeholders were topics of discussion among all who research this area in Jordan (Tweissi, 1999; Jawarneh, 2002, 2007; Al-sa'aideh, 2002, 2008, 2010). The researchers raised concerns that PVE teachers in school were faced with an immense task of teaching PVE which has been launched in schools with dearth of resources and without any inservice provision. One of the constraints cited was the breadth and depth of the subject which seems to be covering a wide array of content across different practical subject disciplines such as Industrial, commercial, agricultural, home economics, and health and safety. The volume of subject knowledge inherent within PVE made it a challenge to teach. Teachers, it was suggested, need to have an in-depth knowledge of a wide range of subject material and be able to apply a wide range of craft skills as well as those of the artist, metalworker, woodworker, plastic worker, etc. Moreover, PVE teachers are required to possess a wide spectrum of knowledge related to various careers and services available in the Jordanian society. The PVE curriculum being used does not have the input of commerce and industry people's contribution so that proper skills are imparted to students as it was developed solely by people from the educational system. The hands-on technique suggested by the Ministry of Education was never adopted by teachers as it was difficult to make such arrangements under severe shortage of resources necessary to make use of such technique. Al-hadidi (1994) stated that the Jordanian society generally are not passionate about blue collar jobs and Vocational Education (VE) due to its social traditions that value white collar jobs and academic education resulting in a serious shortage of labor in associated areas of employment. This social view is, in turn, reflected on any type of general education that goes in line with manual skills and VE such as PVE. Consequently, parents, students, teachers, and principals hold negative views about PVE. The seriousness of the above problems is exacerbated by the fact that there is no systematic identification of the problems and challenges that hinder the effective implementation of PVE, hence the need for this study.

Problem of the Study: Several barriers to practicing PVE teaching at schools were identified based on personal observation of schools' environments and informal discussions with PVE teachers. Among these barriers were the lack of materials, equipment and tools to carry out PVE activities; the lack of administrative support regarding the implementation of PVE; the lack of understanding of PVE objectives and PVE importance on the part of PVE teachers and principals; the neglect of PVE by teachers at schools; and the negative attitudes towards PVE by teachers, students, administrators and parents. The reality is there has been little research on teachers' perceptions regarding barriers to effective implementation of PVE in Jordan. This study will attempt to systematically identify barriers to effective PVE implementation in Jordanian school as perceived by PVE in-service teachers.

Research Objective: This study aims to explore barriers to effective PVE implementation in Jordanian schools as perceived by in-service PVE teachers. In so doing, this study intends to address the following research question:

What are the major barriers perceived by teachers as inhibiting factors to effective PVE implementation at the middle basic school in Jordan?

Significance of the Study: This explorative study will be carried out particularly because of the almost absence of available in-depth scholarly investigations that dig into the underneath facts of the actual reality of prevocational education implementation in Jordanian schools as perceived by PVE teachers. The sound value of this exploration stems from the fact that it will attempt to find out whether the MoE efforts towards investments in technology education represented in the curriculum by prevocational education is justified. Furthermore, the value of this study relies on the fact that, based on analysis of the data that will be obtained from teachers, the researcher hope to pin down the major barriers inhibiting the effective prevocational education implementation in Jordanian schools, and, consequently, to offer some recommendations that may be helpful in directing the implementation of PVE in Jordanian schools. This explorative inquiry is, therefore, needed to shed light on actual in contrast to presumed outcomes of PVE in Jordanian schools.

\section{Literature Review}

Broadly speaking, the main goal of vocationalization worldwide is to improve vocational relevance of education. The goal of improving such relevance is the most important reason why governments introduce practical and vocational subjects into general education. Practical subjects allow students to learn from more active "doing" than what is typical in academic subjects. Therefore, the teaching of practical skills and familiarization with the "world of work" became legitimate parts of general education 
worldwide (Lauglo, 2004; UNESCO, 1974, 2002). Realizing the merits of technical /vocational education in preparing young people for the world of work, several developed and developing countries introduced a practical provision as a core subject in the general education system. The review of the literature show that the provision of equivalent programs to PVE in Jordan worldwide is being taught under several names (Technology Education, Design and Technology, Technology and Design, Basic Technology Education, Handicrafts, Life Skills) and that there are common characteristics across all these provisions. One of the common characteristics cited was the breadth and depth of the subject which seems to be covering a wide array of content, for example in England and Wales, design and technology curriculum include areas like food technology, materials technology, textiles technology, electronics, and communication technology. Another example, the curriculum for Life skills in the Sultanate of Oman covers seven areas of learning: personal skills, citizenship, health and safety, home culture, world of work, social skills and globalism (Ministry of Education, 2012). Another distinct characteristic of this provision is the emphasis on manipulation of tools and materials inherited from past emphasis on crafts. In many countries, such as in England and Wales, this subject still struggles to maintain its position in the curriculum. Other countries, such as Turkey and Netherlands, have integrated PVE (or whatever the name may be) with science education. PVE, however, is making significant progress in countries like New Zealand under the name technology education and in Denmark and Switzerland the subject maintains its craft emphasis. Another common characteristic is that these provisions are heavily dependent on the use of material resources, tools, and equipment and machinery resources. Hence, in the absence of minimally adequate workshops, equipment, consumables, and trained teachers, these practical subjects can easily degenerate into being taught "theoretically" with inadequate attention to practical skills learning, the main emphasis of these provisions.

Due to the wide areas this subject covers, the vast amount of materials and resources, and the need for competent teacher to shoulder its implementation among others, the subject appear to face several problems that militate against its effective delivery in both developing and developed countries. In Kenya, Wafubwa (2011) found that very few of teachers were specialized in teaching Art and Craft, there were almost no teaching materials for Art and Craft, inappropriate teaching methods for Art and Craft. Additionally, he found that the teachers are having negative attitude towards the teaching of the subject. In a similar survey in Nigeria, Aina (2008) found that the teacher quality factor ranked highest out of all the militating factors against the full implementation of the basic technology program. Mandiudza, Chindedza \& Makaye (2013) concluded that vocationalisation in most Secondary Schools in Zimbabwe is mere "window dressing" due to lack of infrastructure, human resources and equipment. Life skills teachers in the sultanate of Oman perceived themselves as less competent in the topical areas of vocational counseling and technical content (Jawarneh, 2013). Benson (2009) concluded that whilst good practice in design and technology is developing in England regarding the implementation of Design and Technology, teacher knowledge remains a significant barrier to effective national practice. Gibson (2007) found that the majority of teachers (73.7\%) believed that the volume of subject knowledge inherent within technology and design made it a challenge to teach because teachers need to have an in-depth knowledge of a wide range of subject material. Among the challenges to implementation of technology education in Australia were limited teacher and student resources (Finger \& Houguet, 2009). Jones, Harlow \& Cowie (2004) reported the main results of a national study conducted to investigate teachers' experiences in the implementation of the technology curriculum in New Zealand schools from years 1-13. Findings indicated that most primary school teachers were aiming for curriculum coverage, had moderate levels of confidence but were concerned about curriculum overcrowding. The results also indicated that Years 7 and 8 teachers were mainly concerned about assessment, whereas secondary school teachers were constrained by existing structures in schools.

The results from the studies relevant to PVE in Jordan revealed a host of problems encountering the delivery and implementation of this subject in Jordan (Al-Sa'aideh, 2002, 2008, 2010; Jawarneh, 2002; Tweissi, 1999; Masri, 1993). Examples of such problems include: Poorly prepared teachers, the lack of facilities required for the delivery of PVE activities, and the lack of administrative support for this subject, and the negative attitudes teachers, students, administrators, and parents hold towards PVE. These studies ascribed the problems hindering the effective delivery and implementation of PVE to the failure of pre and in-service teacher education programs that focus on the de-contextualized delivery of the curriculum content prescribed for teachers in these programs. Teacher education in Jordan faces many problems where lecturing is traditionally used in teacher education institutions (community colleges and universities); crowded classrooms that may be the factor that encourages teacher educators to use only lecturing. In addition, the teaching experience of the majority of Jordanian teacher educators is 
inadequate (Al-Kisswani, 2005; Al-Smadi, 1999). However, the researcher believe that in the case of PVE it is the nature of the subject and the resources it needs, both human and material, that cause its ineffective implementation. The review of research has shown that prevocational education is generally considered to be essential for children in the general education system. A need to familiarize children with technology, life skills and careers is the major emphasis of PVE and synonymous programs worldwide. However, due to the vastness of the subject and the varied amount of resources it needs the literature show that its effective implementation is not an easy task. Studies relevant to PVE implementation in Jordan partly investigated barriers militating against PVE implementation especially at middle basic stage. In addition, a need to enrich the meager research base related to PVE delivery in Jordan was recommended by Tweissi (1999) and Al-Sa'aideh (2002). Therefore, this study intends to thoroughly investigate barriers to effective PVE implementation at the middle basic stage of schooling in Jordan.

\section{Methodology}

Population and Sample: The target population of this study was all PVE teachers in the "North Mazar" educational directorate in the northern region in Jordan $(N=35)$. All teachers in this purposively selected educational directorate were taken as a sample for the study $(n=35)$. However, 29 teachers agreed to take part in the study.

Data Collection Instrument: In this explorative study, the qualitative research method was employed to find out the most problematic issues and concerns viewed by teachers as barriers to effective PVE implementation in Jordanian schools. To examine the research question, the researcher conducted indepth open-ended face-to-face interviews with the study participants. The researcher believed that employing the interviewing technique was more suitable for explorative studies as it gave the researcher freedom to probe more deeply and to extend the responses of the study participants (Merriam, 2009). The interviews were conducted to explore deeply the participating teachers' views and perceptions regarding barriers to effective implementation of PVE at the middle basic stage of schooling in Jordan. The participants were assured of the confidentiality of their responses and that they would only be used for research purposes. As such, the teachers were asked to express freely and honestly their views, concerns and perceptions with regards to the barriers to effective PVE implementation.

Data Analysis: The tape-recorded interviews were transcribed for analysis. To ensure reliability of the transcripts, the researcher gave them back to the interviewees for feedback. All interviewees ascertained that transcripts were consistent with their views, concerns or understandings. None of the interviewees was dissatisfied with what she/he had said. To ensure the content validity of the interview questions, the researcher did his best to prepare the questions carefully, state them as clearly as possible, remain neutral throughout the interviewing process, and conduct the interviews in the most convenient circumstances possible. The form and content of the interview questions were also validated by expert opinions. Such procedures were in line with the guidelines provided by Merriam (2009) concerning the qualitative data analysis. The interviewees were examined thoroughly and deeply. A deep analysis of such responses enabled the researcher to identify the general patterns or themes of the participating teachers' views, concerns and perceptions relating to barriers to PVE implementation in Jordanian schools. Such general patterns of thoughts expressed by interviewed teachers had direct relevance to the purpose of the study. Viewed as such, and after scrutinizing consideration of thematic issues emerged, it was possible to group them into four main categories that were used as bases for the interpretation of issues perceived by teachers as barriers to effective implementation of PVE in Jordanian schools. The names of categories were derived from a combination of what was reflected in the data and based on the literature reviewed (Merriam, 2009). The categories were designed to reflect the purpose of the study and to answer specifically the research question. Frequencies and percentages of such issues were provided.

\section{Findings and Discussion}

This explorative study reports on interviews with (29) PVE teachers. The deep analysis of data obtained from such interviews revealed that the participating teachers' views, concerns and perceptions, interpreted as barriers to effective PVE delivery in Jordanian schools, were categorized into four broad categories of barriers: perceptions and attitudes related barriers, human resources barriers, economic related barriers and administrative barriers. Frequencies were utilized to ensure that each barrier 
achieved an acceptable degree of consensus among PVE teachers in order to be considered as a barrier. In the following sections issues and concerns in each broad category of barriers are discussed:

Findings and Discussions Related to the Problems Pertaining to Perceptions and Attitudes: There appear to be a limited understanding among teachers of what PVE is about. According to teachers PVE is a school subject added to school curriculum to make it more practical or more vocational. Several teachers commented on this as follows: at the time when we were students at schools PVE was barely taught in basic education schools and, if it was taught, it was focused on working with tools and materials that were not available. The only type of tools that were available, as far as I remember, were spades and shovels. We used to make certain maintenance work at schools. PVE teachers at that time used to ask us to clean the school yard during PVE classes or PVE classes used to be occupied by teachers of other school subjects to catch up with their curriculum. Now we are PVE teachers and we do very much the same. The only difference is that there are students' PVE textbooks and more equipment and tools that are mostly outdated. Another teacher commented: I think PVE is about VE. Due to the declining number of students opting for post-16 VE, they introduced PVE to make VE more attractive. But, as you know people in Jordan do not like vocational work or VE due to shame culture and because it limits students' aspirations for university education. In line with this argument, another teacher explained the link between PVE and VE as follows: "Prevocational education means VE as it is hands-on. In metalwork, woodwork, agriculture, home-economics and technical drawing, skills are imparted for students to make things and artefacts."

Undoubtedly, such statements voiced by 26 out of 29 (90\%) respondents clearly pointed to misunderstanding on the part of teachers of the philosophy and intent of PVE. As a consequence of their limited perceptions of PVE, the teachers viewed PVE as being all about hands-on training on how to use technology and make simple artifacts which included workshop processes, learning about the science of materials and solving problems such as repairing and maintaining bicycles and pieces of furniture. Having evolved from traditional craft subjects and been classified as a practical subject, PVE is assumed to be synonymous with $\mathrm{VE}$, the less appreciated type of education after basic education. As such, there is much emphasis on simple motor skills which are heavily dependent on the use of material resources, tools, and equipment and machinery resources. For a long time VE in Jordan has suffered from an image problem (Al-Tweissi, 2013; Masri, 1993). People in Jordan do not encourage their children to join post sixteen VE as it does not usually lead to university education, the type of education that is highly valued by Jordanians. This issue was voiced by 27 teachers (93\%). One teacher commented: parents do not want their children to study the type of manual skills found in PVE. Parents do not consider PVE as a significant school subject. They usually ask about their children's academic progress in maths, science and English when they come to school. I think one of the reasons for this is the presence of the word vocational in PVE and because they hold negative image about VE, this is reflected on the image of PVE at the basic stage." In addition to its affinity to VE resulting in negative attitudes among parents and consequently their children, marks in PVE achieved by students are not counted along with other appreciated school subjects in the students' average marks. This exacerbated the problem of attitudes and perceptions even further among students and their parents. A large number of the study respondents, 25 out of 29 (86\%), reported that, overall, students in the Jordanian schools lack interest in PVE because the marks assigned for PVE are not significant for entry to a higher level education.

An example of comments reported by teachers illustrating this issue: students consider PVE unimportant for their preparation to take General Secondary Education Examination (GSEE), the examinations for entrance into the university. Students don't seem to care about anything which is not leading to a university degree. I find it extremely difficult to attract students' attention during PVE classes. We suffer a lot to attract attention of students. Students have no interests in PVE classes. I think this is firstly, due to the problems of lack of resources and materials; teachers usually resort to teaching the theoretical aspects of PVE with little or no student practical activities. Secondly, teachers normally assign students' grades in PVE randomly without really assessing them because students' marks in PVE are not considered important by students and their parents. Math, English and sciences-dominate the timetable at schools and help sway people to believe academics is the more lucrative or honorable pathway to success in life. I think this is the general trend in Jordan. It seems that there is a lot of emphasis on the part of teachers on the delivery of PVE theoretical aspects mainly due to lack of resources required for the delivery of practical aspects of PVE. Children at this age learn more by doing. Learners need to be allowed to be adventurous and enabled to enjoy teach (Carmen, 2008). The more the teacher talks, the more passive students become in learning and the less motivated they become about learning the subject. The emphasis should be on projects which will cover the outlined technology areas. In support of these 
sentiments. Fox-turnbull and Snape (2011) argues that in a technology-based curriculum, students learn best by doing, with an emphasis on problem-solving. Another important point that contributes to students' lack of interest in PVE is the emphasis on the theoretical aspects in the implementation of PVE. Comments hinting to this issue were voiced by 25 teachers (86\%). An example of such comments as portrayed by one teacher: in PVE classes, we create artificial learning environments for our children that they know to be contrived and undeserving of their full attention and engagement. Students should be given the opportunity to learn through the hands, otherwise the world remains abstract and distant, and the concern for learning PVE activities among students will not be achieved.

The problems of negligence and carelessness facing PVE are further aggravated by schools' administrators' lack of awareness and understanding of PVE. The non-supportive schools' policy and the lack of understanding among schools' administrators regarding the philosophy and objectives of PVE were mentioned by 23 teachers (79\%) as major barriers hindering the effective implementation of PVE. One teacher explained: I have been asked several times by the school administrator to leave PVE lessons for teachers of other subjects like science, mathematics and English Language, who lag behind regarding their curriculum coverage in order to catch up with the teaching of their subjects. Worse than this he, the school principal, ask us to order students to clean the school yards and buildings instead of delivering PVE lessons and activities. From what I said I think it is easy to infer what schools' administrators think of PVE. Patterns of behaviour of those directly involved in the implementation of PVE designates the beliefs of other people in the schools; PVE teachers and principals perceptions of PVE dictate how parents, students, and other teachers in the schools perceive PVE (Dovos, Dupriez \& Paquay, 2012; Charland, 2011). This is a clear indication that schools give less importance to PVE as opposed to other subjects in the schools. This can be traced to the old misconception, which is still holds, that practical subjects are appropriate for the students who are less intelligent and intend to follow VE after basic education (Tweisat, 1998). The classification of PVE as a practical subject in the basic education school curriculum is assumed to be synonymous with VE, the less prestigious type of education after basic education. As such, much emphasis is on simple resistant material's motor skills and outdated activities which act as a deterrent for most students.

The barriers of low perception and negative attitudes towards PVE appear to exist among all the parties concerned with the delivery of PVE. Twenty three teachers (79\%) of the respondents were more frank in delineating the problem of negative attitudes and perceptions. According to them, higher education institutions responsible for teacher preparation were to blame. One teacher commented: although outdated, many schools, including our school, have tools and equipments that can be used to deliver some of the practical activities related to the industrial area of PVE such as metal work and wood work, but we have not been trained nor educated on how to deliver PVE practical activities. We teachers do not like to deliver the practical activities we even hate to do so because of our inability and because it takes a lot of preparation and efforts. One of the long-standing problems that negatively affected the delivery of prevocational education in Jordan is society's attitude towards practical and manual skills. It is long understood that the place of manual skills and vocationally oriented activities are greatly affected by the system of values and norms prevailing in that society (Masri, 1993). The natures of the skills which have dominated the practices in PVE since its introduction in 1979 have also fostered a widespread sense that PVE is of inferior status. The presence of outdated skills and activities and the emphasis on low paid jobs have contributed to this. Many people in education, including teachers and principals, consider practical and productive activities within general education with great suspicion as extraneous and unwanted activities compared with theoretical academic areas they favour and are accustomed to. In addition they view any practical activities as interfering with the calmness of the routines they are familiar with. Such an unfavourable view has resulted in several failures of attempts to establish such activities in general education system. Schools' administrators and the teaching staff have stood firmly against any endeavour in this direction, sometimes pointing the finger of blame at the lack of facilities and the inefficiency of legislation and regulations on the other.

There is also the problem of a limited and narrow understanding in the minds of educationists about the nature and the place of PVE within the general education system as regard to its intentions and objectives. One of the ideas that has dominated the practices at schools dealing with PVE as a stand-alone subject, separate from any other subject within the school, perceives manual skills and practical activities as having no social and economic benefits. There has been a lack of overall vision among school administrators and teaching staff to consider PVE as more than an addition of another subject with certain number of teaching hours to the schools' study plan. The all-inclusive and open-minded view of 
PVE within general education is that which puts emphasis on the relationship of PVE with all other subjects within the school in addition to other extra-curricular activities to facilitate the acquisition of knowledge, information and attitudes needed. Many educational systems still lack this broader view when dealing with PVE within the general education system. The short-sightedness and negative attitudes in the perspectives of the authorised personnel towards PVE in the education system are reflected in the general attitudes and perceptions in society. Furthermore the students, due to this backward view, shun this subject as it is associated with out-dated trivial manual skills deemed to have no social and human benefits.

Findings and Discussions Related to the Problems Pertaining to Economic factors: Based on the analysis of the responses of PVE teachers another important category of barriers emerged. That is economic related barriers. Economic related barriers are those related to lack of resources thereby inhibiting the effective delivery of PVE. Resources include anything that can be used as educational tools which if present facilitate the effective delivery of PVE. In the context of this study, resources refer to the following: materials used in the actualization of products and artefacts; tools and other electronic and mechanical equipment used to manipulate materials when actualizing products included in PVE curriculum. The teachers mentioned that the schools lacked support towards the provision of teaching and learning resources and the problem was seen as impacting on the teachers' pedagogical practices and students' learning of PVE skills. Due to the problems encountered, teachers resorted to teaching the theoretical aspects of PVE relating to industrial, agricultural, commercial, home economics, and health and safety areas with little or no student practical activities. The majority of the respondents 27 (93\%) said that tools and equipment in the schools were not adequately replenished and there had been no maintenance of machines, rendering most of them obsolete and unusable. This barrier was depicted by one teacher as follows: Most of equipment and tools in metalwork and wood work are not in a good condition. As a result, we give students very little practice. In agriculture and other PVE curricular areas we do not have any relevant equipment and tools. For instance, how can we teach students about trees pruning and grafting if we do not have a school garden or trees to do that?

The absence of physical infrastructure and equipment in many schools drives the focus of the examination strongly toward theoretical contents in what should be a practical subject, and much of the theory tested is memorization of factual material rather than ability to interpret and apply. These features of the examination tend to reduce what should mainly be learning of practical skills, to memorization of facts. There is emphasis on knowledge and understanding of subject matter, insufficient attention to practical skills; and teacher's inability to apply newer assessment approaches such as criterion-referenced assessment or portfolio-based assessment. We just concentrate on theory because materials are not there and when we want to assess students to assign those grades, we ask them to bring any artefact from home. In addition we assess students on the theoretical aspects of PVE lessons that we cover during a semester. We do not assess students on the practical aspects of PVE. Even if we want to assess students' practical abilities relevant to PVE, there are no guidelines on how to do that. The teachers showed that the situation influenced them in making appropriate pedagogic and assessment decisions in light of the unavailability of resources. This also impacted on assessment practices. The overwhelming majority $28(97 \%)$ of teachers also expressed dissatisfaction in the way the subject was implemented. An example of comments made by teachers expressing this situation: I think there are some useful skills in PVE curriculum but I do not like the way the subject is being handled. We do not get the support we need. At the end of the day we just teach students because PVE is a required school subject at the middle basic stage level"

Lack of materials, tools and other equipment relevant to PVE teaching also affected students' perceived level of difficulty of PVE and the way the subject is implemented. This is reflected in the following comments made by teachers: Yes PVE activities are difficult for students to understand because we teach them theoretically due to lack of tools and materials." Current PVE teaching practices were viewed as not helpful and do not add much to students' knowledge and expertise. A large number of respondents, 26 out of $29(90 \%)$ teachers attributed this situation to lack of resources. One teacher commented: I think for effective delivery of PVE, an awful lot of materials, tools and equipment related to the five areas of PVE should be available but as you see there are some outdated tools and materials related to the industrial area of PVE and nothing for the remaining four areas of PVE such as home economics, agricultural, commercial and personal safety and hygiene. Resources in PVE include tools, equipment, machinery, materials, workshops, a school garden and other specialist rooms. Resource constraints include shortage of resources as well as poor or insufficient maintenance of such resources. When asked if they had 
enough PVE related resources in their schools, 27 teachers out 29 (93\%) indicated that there was shortage of resources in PVE. These teachers also indicated that most of the tools available were not safe to use due to poor or insufficient maintenance, for example, one teacher commented that: Even the tools which are there, most of them are just not safe to use even though we just use them in the delivery of some PVE activities related to metal and wood work."

Most of the schools visited utilise the workshop facilities as warehouses rendering their exploitations in the delivery of PVE activities very difficult. Such schools' practices results in several problems among which the restrictions of students' movements due to narrow floor area, reluctance on the part of teachers and students to perform practical activities for fear of the danger caused by random layout of scrap not to mention putting down the already shaky status of PVE in the eyes of students and teachers. This barrier was mentioned by 24 out of 29 teachers (83\%). One of the teachers mentioned this problem and its resulting disadvantages as follows: The effective use of available PVE related resources in schools is further hindered by the negative practices of schools personnel. Workshops space is used as a dumping ground. Unused chairs benches, devices are usually stored in workshop spaces. I and my students find it difficult to move and perform in the remaining space. I also find it dangerous to work under such circumstances." The relatively high costs of infusing the general education system with vocational and practical activities and providing the required facilities and services pose a formidable financial challenge to the educational institution that cannot be underestimated.

Findings and Discussion Related to the Problems Pertaining to Administrative Factors: Regarding PVE programmes administrative problems arise when the schools are deprived of any initiative and their role is restricted to ready-made programmes and instructions planned and designed at the top level of authority. Consequently schools are not active participants in the design and implementation plans for the vocational activities prescribed to them. That is to say schools are not partners in the process of identifying the content of PVE programmes so that a reasonable degree of harmony can be achieved between schools' facilities, capabilities and the surrounding environment on the one hand, and the content of these programmes on the other. This important issue was voiced by all teachers, 29 out of 29 $(100 \%)$. One teacher commented: The usual practice in the delivery of PVE activities is, as stated earlier, to use an already designed curriculum developed at the MoE without teachers' participation and forced on the schools without time for the schools to prepare to implement such programmes resulting in high degree of inconsistency between the intended outcomes and what can be achieved on the ground".

The top-down curriculum approach has a lot of weaknesses because it lacks teachers' participation in the determination of its content. Any curriculum initiative should consider teachers as key players. However, it appears that the PVE teachers have no role to play at any point in the PVE curriculum development process. Teachers feel PVE curriculum has been imposed on them. Worldwide experiences provide evidence that changes in the technology curriculum have been successful only when initiated by technology teachers (Barnes, 2005; Mandiudza, Chindedza, \& Makaye, 2013). Therefore, teacher's perceptions are central to an understanding of curriculum development and change otherwise they may super impose their own different interpretations of educational philosophies. Moalosi and Molwane (2008) assert that in implementing any educational reforms, the attitudes of teachers determine the success or failure of any innovative curriculum. Teachers must agree with the underlying philosophy of the curriculum. However, a broader view was given by Kahn and Ullah (2008) who indicates that a rich meaning-centred curriculum requires a close collaboration of all stakeholders in educational reform such as teachers, students, administrators, parents, researchers, business community, curriculum specialists and technology developers.

Overall it was seen that implementation of the PVE curriculum was impacted by policy and the state of the curriculum. As the subject was deemed insignificant at the ministerial level and consequently at the school level, schools' principals would rather use resources and source support for other school subjects such as science, mathematics, and Language (both Arabic and English). The curriculum was also viewed as old, with a focus on outdated skills rather than imparting thinking skills that would enable students to develop confidence and capabilities to solve problems. The outdated curricular content was hinted to by 27 teachers out of 29 (91\%). One teacher explained: The PVE curriculum content is not up to date. I think the content has not been changed since the introduction of PVE in the basic education schools in 1980. One of PVE objectives is to keep students abreast with recent technological innovations but we do not see this translated in the PVE curriculum content". Some teachers, 17 out of 29 (59\%), stressed that caution should be exercised when developing PVE curriculum by making it more technologically relevant by not 
discarding the critical elements of the traditional curriculum. Examples of statements supporting this were: The diversified use of different materials, new work methods, and technology should nonetheless be realized without losing some of the traditional skills in the curriculum such as woodworking. In PVE the making of products is also important. The subject may not only be going toward recent technological innovations. The making of concrete articles and artifacts is very essential for students' developments".

"Certain basic skills, techniques and traditional tasks should be saved at the same time the PVE curriculum should include skills related to computers and mobile phones. You know, our students nowadays use laptops and mobile phones. These technological tools should be emphasized in the PVE curriculum in order to make PVE more attractive and relevant to students' lives". If the curriculum content is not to be modernized, it will lose the attractiveness to be learned by students and this will perpetuate the negative attitudes parents, students, and teachers hold towards PVE. Therefore, there is a need to review the content of PVE curriculum in a way that produces contemporary and relevant content that is useful to student's daily life. PVE is founded on competencies and manual skills that were relevant to the Jordanian society needs during late seventies and early eighties of the last century. This position carries with it a stigma, a history that may render the subject out of date in the 21st century curriculum. PVE curriculum should be revamped and be founded on up-to-date technology, which everybody needs in this technology driven society.

The ministry of education in Jordan stipulates that content delivered in PVE is intended to be the same regardless of students' gender (MoE, 1995); however, gender stereotypes related to PVE activities implemented in schools are strongly alive. All the visited schools have gender biases in the type of PVE areas they deliver. Male schools gravitate towards implementing PVE areas that are associated with traditionally male occupations. The implementation of industrial and agricultural areas in PVE is prevalent in male schools. Home economics area in PVE is exclusively implemented by female schools. The available PVE related facilities, teachers' specialties and students' preferences dictate the kind of PVE activities implemented in schools. A large number of the study respondents, 27 out of 29 (93\%), reported the existence of gender stereotypes in the Jordanian schools. A teacher portrayed the situation as follows: I do not see why the ministry of education still insists on similar PVE curriculum for both boys and girls. Girls like to perform the PVE activities that are similar to what they do at home. They like cooking and making pastries and they have the resources to implement such activities. Their specialties as PVE teachers and the resources available at school they teach in are in line with home economics area of PVE. In male schools, we do not implement any of the activities related to home economics" There is a difference between male and female schools regarding the content that can be delivered to students. This difference is implied by the facilities available in workshops of each type of schools (Al-Sa'aideh, 2002, 2008; Tweissi, 1999). They suggested that the difference could be ascribed to the difference in qualifications between female and male teachers; most of the female teachers are specialized in home economics, while most of male teachers are specialized in PVE agriculture, or other vocational specialization. This gives advantages for male schools to deliver a variety of PVE areas over female schools.

Classes in Jordanian schools are overcrowded with students; even in newly built schools, the number of students in a class ranges between 35 to 50 students (Al-Sa'aideh, 2008). The spaces allocated for PVE workshops are identical in all schools regardless of the number of students. Thus, even if teachers intend to train students on practical activities, they find it difficult to accommodate students in the workshop. The large number of students in a class also impedes teachers' ability to ensure safety in the workshops. This issue was raised by 25 out of $29(86 \%)$ teachers. One teacher explained: Class size hinders our ability to perform practical activities and makes it difficult for us to ensure the safety of all. You know, in small classes more time could be given to individual pupils, and the chance of pupil access to machines and other specialized equipment increases, what is available of them anyway. The recommended number of class-periods for PVE from the Ministry of Education is two class-periods per week but some schools only offer it for one class-period and some schools do not offer it at all. Teachers suggested that the time allocated to this subject created further barriers considering the nature of the activities included. A majority of the teachers agreed that PVE at the middle basic stage of schooling was too demanding of curricular time if it is to be implemented properly and the time allocated for its teaching is not sufficient. In addition to insufficient time, teachers mentioned another barrier related to the breadth and depth of the subject which is covering a wide array of content from across a wide range of practical areas such as agriculture, industry, home economics, commerce and health and safety. Teachers argued that more time was necessary to ensure that the demands of the programme of study could be met or the curricular 
content should be abridged. The concerns related to time and the length of PVE curriculum were voiced by 24 teachers out of $29(83 \%)$. A representative comment related to these two concerns is portrayed by a teacher as follows: if PVE lessons and activities are to be delivered in accordance with the curriculum guidelines, more time is needed. The time allocated for the subject is not enough to train students on the practical activities included in the curriculum. If an increase in the time allocated for the subject is not possible, a reduction in the curricular content is a must.

However, because of its low status and the way it's being delivered in schools these barriers do not pose any challenge to PVE teachers.

The Teacher Training Department in the Ministry of Education, which is tasked with running in-service courses, is not effective in carrying out its mandate relevant to PVE teacher training. This has resulted in teachers not teaching PVE at all or teaching modules they are comfortable handling. Resources in PVE include tools, equipment, machinery, materials, workshops and other specialist rooms. Teachers' lack of knowledge about maintenance procedures of the PVE related equipment and devices was mentioned as a great barrier to PVE delivery. PVE teachers have neither been trained during their preparation nor during their in service on how to operate or maintain PVE equipments and machines. This issue was raised by all teachers $(100 \%)$. One teacher commented: We have not learnt such skills when we were at college or during our teaching experience. Most of us have limited or no experience with the pedagogical practice related to machining processes during pre-service or the in service training programs conducted by the MoE. Teacher training programmes both pre-service and in service should include more technical pedagogy, machine maintenance, and industrial experience in order for PVE teachers to deal with the available PVE resources". Due to the variety of topics included in the curriculum (industrial, business, home economics, health and safety, and agriculture), teachers are not able to train students on all these topics, particularly practical skills. Therefore, the problem of lack of capability could be overcome by training teachers on the skills of these five fields. These concerns were voiced by all teachers. In the words of one of the teachers: PVE is a vast subject and therefore requires a comprehensive teacher who acquires good experiences in all topics. This is difficult because every teacher has one specialty. There is an urgent need for periodic in-service training of PVE teachers. In- service workshops should be organized to equip PVE teachers with the necessary skills to handle and effectively implement the five fields of the curriculum.

In their book 'How people learn', Bransford, Brown \& Cocking (2004) concluded: Outstanding teaching requires teachers to have a deep understanding of the subject matter and its structure, as well as an equally thorough understanding of the kinds of teaching activities that help students understand the subject matter in order to be capable of asking probing questions" (p. 188). This quote implies that subject-specific teacher knowledge in general is important for successful PVE delivery. PVE teachers, who are educated to teach a wide variety of PVE areas, will therefore need a thorough understanding of the subject matter of all PVE areas to know which topics to address and how to address them in their PVE lessons (Rohann et al., 2010).

Findings and Discussion Related to the Problems Pertaining to Human Factors: One of the major stumbling blocks to the delivery of PVE as a stand-alone subject is the impossibility of making available a qualified teacher capable of implementing the requirement of this subject. This is because of the considerable number of practical activities and skills included in this subject, together with the theoretical information and scientific basis supporting these activities. The syllabus for PVE at the middle basic education stage includes units relating to five different PVE packages, that is agriculture, industry, business, home economics, health and safety. From the context of this subject and experiences, students are expected to acquire and be exposed to a vast array of content possibilities. All teachers, 29 out of $29(100 \%)$, hinted that it is extremely difficult for one teacher to shoulder the responsibility of delivering this subject. This was expressed in the words of one teacher as follows: all of the teachers employed to teach the subject cannot handle the teaching of all the PVE areas. It is very difficult for PVE teachers to be specialized in the five areas related to PVE. A teacher can teach one area. For me I teach the area which I feel comfortable with". All the schools visited appeared to be faced with staffing problem. Teachers with different specialties are assigned to teach PVE. Some of the teachers are specialized in PVE teaching while others have backgrounds that are not directly relevant to PVE. Twenty-Four out of 29(83\%) teachers expressed similar concerns. This was best described in the words of one PVE teacher whose specialty is physical education: PVE classes are so watered down by teachers with varied background that don't know what they are doing. I my myself being assigned as PVE teacher even though my specialty is 
physical education. I knew very little about PVE. I teach PVE and have never been trained in it. Because nobody cares about this subject we just teach it haphazardly."

Lack of teachers with specialist skills to teach the subject, and lack of in-service professional support, is prevalent barriers on implementation of PVE. Again the PVE equipment and machines that are available in some schools are laying waste not because they are, sometimes, not functional but because the available teachers can neither operate nor use them due to their inability and lack of confidence. The teaching of PVE and students' attitudes towards PVE are greatly affected by teacher knowledge (Rohaan, Taconis \& Jochems, 2010). Teachers with low confidence becomes frustrated about keeping their knowledge and skills updated and fails to encourage pupils which in turn lead to a negative attitude towards the subject they teach (Davies, 2000). In general, a teacher who has a negative attitude towards PVE or has little confidence in teaching PVE, reflects this in the classroom, and in turn affects pupils' attitude towards PVE. Teacher education should first focus on forming positive attitudes among PVE teachers and then on empowering them to teach the subject (Johnston \& Ahtee, 2006). In addition to lack of specialized subject teacher, there is a general lack of qualified supervisors. Supervisors are appointed by the MoE to monitor the implementation of teachers' instructional roles to ensure that they prepare their lesson plans and notes in line with the curriculum objectives and deliver them in conformity with the allotted time range. PVE teachers mentioned that many of the supervisors do not have adequate experience and professional background relevant to all PVE areas. This situation should have been foreseen in that the previous qualifications and experience of many of the supervisors are relevant to one of the PVE areas. Thus, they are ill equipped and not in a position to guide PVE teachers on the proper implementation of PVE areas dissimilar to their background specialties. This issue was voiced by 23 out of $29(79 \%)$ teachers. A teacher portrayed this issue as follows: I am a PVE teacher with a background in agriculture. The supervisor who comes to school once in a year holds a bachelor degree in commerce so how can he guide me on the agricultural area of PVE. I am better equipped than him in this area".

As part of their administrative role, PVE teachers' supervisors are expected to conduct regular in-service training workshops for PVE teachers to enable them to effectively teach PVE. However, there seems to be a misunderstanding of the relationship between teachers and supervisors; only one supervisory visit during the academic year, and the concentration of the supervisors on the weaknesses they found in the teacher's performance rather than advice and guidance to the teacher or providing feedback from the field to help in policy improvements (Al-khashman, 2000). Lack of knowledge of other schoolteachers' especially teachers of mathematics and science of the interrelationship between their subject and PVE negatively affects the implementation of PVE activities. The other teachers in the school do not see the relevance of PVE activities to their subject areas. The analysis of PVE curriculum reveals a significant resemblance between PVE activities on one hand and science and mathematics on the other (Batarseh, 1995; Al-Sa'aideh, 2010). Most of PVE activities are based on scientific and mathematical principles. However, science and mathematics teachers are not cognizant of this close relationship and look down on PVE and even PVE teachers themselves. This concern was asserted by 21 out of 29(72\%). In the words of one teacher: There is a considerable degree of resemblance between PVE and other school subjects especially science and mathematics. Science and mathematics teachers look down on PVE and on us as PVE teachers not aware of this resemblance. There is an amble of opportunities for integration between PVE and these two highly appreciated school subjects. If effective implementation of PVE is to be achieved, professional development of those teachers should include experiences that integrate PVE with science and mathematics. This I think will make PVE more attractive in the eyes of students, parents, teachers and schools' principals.

\section{Conclusion and Recommendations}

The interviews and informal observations done showed that the implementation of PVE in basic schools is an uphill struggle. The study also revealed that the negative perception of PVE perpetuated from the era of early eighties of the past century still prevails and affects negatively the implementation of this subject. To make matters worse on the implementation, teachers, students and parents still hold the idea that students who do PVE are not academically talented and students' chances of accessing higher education is extremely limited. Teachers who teach PVE are looked down upon just as the subject they teach. In the end this subject loses popularity since teachers who are responsible for teaching it develop an inferiority complex and parents feel that the success for their kids would only come with a university degree through academic type of schooling. All stakeholders, especially parents and students, are to be convinced of the necessity to change their perceptions about and attitudes towards PVE. Based on the 
discussion above and considering the social culture prevailing in the society, the most important way to convince parents and consequently students to change is by including PVE in the university entrance examinations GSEE. Subjects to be studied by students like PVE should not just be imposed on them. All should be allowed to see the benefits to be gained in order for them to change. The name prevocational education is expected to remain a source for negative attitudes towards this subject among all stakeholders because it contains the world vocational. Hence, it is advisable to change the name to more attractive one and to modernize the content to be in harmony with the needs of a technological society.

It appears that the beliefs of teachers, students, parents and principals have impeded effective implementation of the PVE curriculum. Such beliefs have hampered effective implementation of similar programs even in countries where practical subjects similar to PVE were an established learning areas (Ugras \& Cil, 2012; Gibson, 2007; Després, 2011). However, as (Sherman, Sanders \& Kwon, 2010) asserted, understanding and then incorporating such beliefs in all phases of PVE curricula planning, development and implementation process, including professional development programs, may be an alternative way to alleviate such barriers and improve teaching of PVE. Teachers lacked technical and content knowledge related to machine maintenance and they also lacked skills to operate some of the machines such as lathes. The teachers said that they had not learnt such skills when they were at University. The teachers attributed this problem to their limited experience with and pedagogical practice related to machining processes during their pre-service training. The teachers suggested a review of teacher training programs to include more technical pedagogy, machine maintenance, industrial experience, and enough teaching practice exposure. In the future, student teachers need an energetic approach to PVE. They should be given more time to practice the technical skills relevant to all PVE areas. The analyses of the curriculum of PVE for students at the middle basic stage reveal a high degree of overlap with the curriculum for the more specific VE (Al-Sa'aideh, 2002, 2008, 2010). This includes the level of the skills and theoretical information contained in the PVE curriculum and the VE curriculum. Therefore, PVE teachers should be prepared in the same way as the more specific vocational teachers in one field relevant to PVE. To be able to contextualise PVE activities, teachers should be attached to factories, industry for a real production environment and practice.

Due to poor economic situation, there are major shortcomings in Jordan's capacity to finance and implement vocationalization. PVE has been very severely underfunded since its inception into general education system, and the studies relevant to this subject, (Rawagah, 1994; Tweissi, 1999; Al-Sa'aideh, $2002,2008,2010$ ) are non-optimistic about its effectiveness. On the one hand, policies were driven by the political desire to make schools more "relevant" for economic life and by the conviction that this should be achieved by introducing PVE in all schools. On the other hand, implementation has been constrained by high costs and greater logistics complexity than other subjects. What was supposed to teach practical skills all too often has ended up being reduced to theory teaching. The Objectives of vocationalisation of schools cannot be achieved if PVE is taught like academic subjects due to lack of resources and incompetent teachers (Lauglo, 2004). The MoE, before adopting any changes, should make sure resources; both human and material are made available. PVE teachers expressed the view that the curriculum had remained the same over the years despite technological advancement and that the curriculum emphasised manual skills training at a time when facilities were out of date and with inadequate provision of teaching and learning materials. Hence, a review of the curriculum is needed to provide content that is responsive to global changes in technology and focus on students thinking and their ability to solve problems while retaining some of its skill-based emphasis. Schools should be consulted during the process of planning, designing and specifying the content of PVE in harmony with their capabilities. In addition, a follow-up plan should be designed that emphasises continuous updating and improvements to ensure the adaptation of the experience to the needs of society.

The study revealed that societal beliefs and stereotypes may have affected both boys' and girls' schools choices of PVE learning areas as most girls' schools opt for home economics and health and safety areas while most boys' schools opt for industrial, agricultural, and commercial areas of PVE. The researcher believes that this trend is likely to remain in the foreseeable future. Gender divide related to the technological area selected can be observed in both developed and developing countries (Autio, Ruismäki \& Hietanoro, 2007). Therefore, different curriculum for males and females should be developed in harmony with schools' capacity both human and material. It is unsurprising that there is a general consensus among those who conducted research on PVE efficiency and effectiveness in Jordan (Tweissi, 1999; Al-sa'aideh, 2002; Ahmed \& Al-Sa'aideh, 2007, 2008; Doghlos, 2004), that it is extremely difficult for one teacher to shoulder the responsibility of teaching PVE. Therefore, the traditional team teaching 
approach identified by Al-Sa'aideh (2010) where teachers, especially science and mathematics teachers in addition to PVE teacher, collaboratively share the instruction of content and skills to all students is a viable option to the implementation of PVE. In addition to tackling the issue of incompetent teacher, this approach may contribute to changing the traditional image of PVE by pairing it with the highly valued school subjects. Science, Technology, Engineering and Mathematics (STEM) are another viable approach to the delivery of PVE at basic education in Jordan. STEM is an interdisciplinary approach to learning where students are exposed to real-world lessons as they apply science, technology, and mathematics to authentic situations (Tsupros, Kohler \& Hallinen, 2009). The study recommends a re-education of the whole nation on the value of PVE and VE. Although there are policies guiding the implementation of PVE there is need of strict policy adherence by all stakeholders.

\section{References}

Ahmed, E. \& Al-Saaideh, M. (2007). Situations that force teachers of pre-vocational education to deliver it theoretically in Jordan. Journal of the Faculty of Education, Ain Shams University, 31(4), 12-28.

Ahmed, E. \& Al-Saaideh, M. (2008). The degree of focus on the practical skills in teaching of pre-vocational education in the schools of Al-balqaa governorate. Journal of Damascus University for Educational Sciences, 42(4), 38-62.

Aina, 0 .C. (2008). Technical and Vocational Training as a strategy for Technical Development. Journal of Teacher Education of Nigeria, 1(1), $129-136$.

Al-Hadidi, D. (1994). Problems facing female pre-vocational education teachers at the basic stage schools in the capital. Unpublished Master Thesis. University of Jordan, Amman.

Al-Khashman, A. (2000). The Role of Supervisors of Pre-vocational Education in Improvement of Teachers' Performance as Perceived by Teachers in the Capital of Amman. Unpublished Master Thesis, the University of Jordan, Amman.

Al-Kisswani, A. (2005). Building a model for curriculum development for home-economics in the comprehensive secondary education that satisfies the requirements of knowledge economy and Jordanian labor market, unpublished PhD dissertation, Amman Arab University, Amman, Jordan.

Al-Sa'aideh, M. (2002). Pre-vocational education in Jordan: Implications for teacher education and inservice preparation. Unpublished Ph.D. Thesis, University of Huddersfield, England.

Al-Sa'aideh, M. (2008). Actions Proposed by Teachers to Improve the Delivery of Pre-Vocational Education in Jordan. Journal of Instructional Psychology, 35(4), 317-335.

Al-Sa'aideh, M. (2010). A Rationale to Adopt Team Teaching in Prevocational Education in Jordan. Journal of Instructional Psychology, 37(4), 269-285.

Al-Smadi, Y. (1999). Evaluation of the 'class-teacher' pre-service teacher education programme at the University of Jordan. Unpublished PhD Thesis, University of Sussex, U.K.

Al-Tweissi, A. (2013). Effects of Prevocational Education on the Vocational Knowledge and Attitudes of Students-Teachers in Jordan. Journal of Education and Vocational Research, 3(1), 1-8.

Atsumbe, B., Raymond, E., Idris A. \& Mele, E. (2012). Retraining Needs of Technical Educators for the Implementation of the Junior Secondary School Basic Technology Programme in Nigeria. Journal of Mechanical and Civil Engineering, 1(4), 7-13.

Autio, 0., Ruismäki, H. \& Hietanoro, J. (2008). The touch of technology - gender equity and factors in students' motivation. In: ISATT 2007 - conference proceedings: [the 13th Biennial Conference of the International Study Association on Teachers and Teaching (ISATT), July 5-9, 2007, St. Catharines, Ontario, Canada]

Barnes, R. (2005). Moving towards Technology Education: Factors that facilitated teachers' implementation of a Technology curriculum. The Journal of Technology Education, 17(1), 6-18.

Batarseh, M. (1995). Integration between pre-vocational education and other school subjects. A Paper Presented at the National Circle on Upgrading the Competence of the Pre-vocational Education Teachers and Supervisors, 15-20 July 1995, UNESCO, Amman, Jordan (in Arabic).

Benson, C. (2009). Design and technology: a 'new' subject for the English national curriculum. In A. Jones \& M. J. de Vries (Eds.), International handbook of research and development in technology education (pp. 17-30). Rotterdam: Sense Publishers.

Bransford, J., Brown, A. \& Cocking, R. (Eds.). (2004). How people learn: Brain, mind, experience and school. Washington DC: National Academy Press.

Carmen, C. (2008). Model Program: Technological Education in Ontario Schools. The Technology Teacher, 67(4), 28-33.

Charland, W. (2011). Art integration as school culture change: A cultural ecosystem approach to faculty development. International Journal of Education \& the Arts, 12(8). 
Després, B. (2011). Technology Education Issues in British Columbia. Retrieved May10,2012fromhttp://www.cvaacfp.org/en/pdf/Occasional_Paper_BlaneDespres_TT08Discuss ion111115.pdf.

Dughlos, A. (2004). The Situation of the Curriculum Implementation of Pre-vocational Education in the Higher Basic Stage in Jordan. Unpublished Ph.D. Dissertation, the University of Jordan, Amman.

Dovos, C. Dupriez, V. \& Paquay, L. (2012).Does the social working environment predict beginning teachers' self-efficacy and feelings of depression? Teaching and Teacher Education, 28, 206-217.

Mandiudza, L., Chindedza, W. \& Makaye, J. (2013). Vocationalization of Secondary Schools: Implementation Reality or Fallacy? European Journal of Sustainable Development, 2(1), 123-132

Finger, G. \& Houguet, B. (2009). Insights into the intrinsic and extrinsic challenges for implementing technology education: Case studies of Queensland teachers. International Journal of Technology and Design Education, 19(3), 309-334.

Fox-Turnbull, W. \& Snape, P. (2011). Technology teacher education through a constructivist approach. Design and Technology Education: An International Journal, 16(2), 45-56.

Gibson, K. (2007). Technology and Design at Key Stage 3: perceptions of challenge. Design and Technology Education, 12(1), 55-64.

Hendrix, M. (1986). Prevocational education implementation manual. Texas Education Agency, Austin, USA.

Jawarneh, T. (2013). Life Skills teachers' readiness for their role: implications for Higher Education. Learning and Teaching in Higher Education: Gulf Perspectives, 10(1), 42-58.

Jawarneh, T. (2002). The Delivery of Pre-Vocational Education in Jordan in Relation to the United Kingdom's Part One General National Vocational Qualification. Unpublished Ph.D. Thesis, University of Huddersfield, England.

Johnston, J. \& Ahtee, M. (2006). What are Primary Student Teachers Attitudes, Subject Knowledge and Pedagogical Content Knowledge Needs in a Physics Topic? Teaching and Teacher Education, 22(4), 1-10.

Jones A., Harlow A. \& Cowie B. (2004). New Zealand teachers' experiences in implementing the technology curriculum. International Journal of Technology and Design Education, 14(2), 101-119.

Kahn, T. M. \& Ullah, L. K. T. (2008). Learning by Design: Integrating Technology into the curriculum through student multimedia design projects. New Horizons for Learning Online Journal, 12(2).

Lauglo, J. (2004). Vocationalized secondary education revisited [draft paper]. Available at http://siteresources.worldbank.org/INTAFRREGTOPSEIA/Resources/paper_Lauglo.pdf

Masri, M. (1993). Pre-vocational education. In Masri (Ed) Introduction to Education. Amman, Jordan: Dar Al-Shorouq.

Merriam, S. (2009). Qualitative research: A guide to design and implementation. San Francisco: JosseyBass.

Ministry of Education. (2012). Curriculum Documents for Life Skills Curriculum. General Directorate of Curriculum and Education Technology, MoE, Muscat, Oman.

Ministry of Education. (1988). The First National Conference of Educational Development. Teacher's Message, 3(4), (in Arabic).

Ministry of Education. (1990). Pre-Vocational Education Curriculum and Its Guidelines in the Basic Education. General Directorate of Curriculum and Education Technology, MoE-Jordan.

Ministry of Education. (1993). Vocational Education Guide. General Directorate of Vocational Education at The Ministry of Education, MoE, Jordan.

Ministry of Education (MoE). (1995). Pre-vocational Education: Special Report. General Directorate of Vocational Education, Ministry of Education, Amman, Jordan.

Moalosi, R. \& Molwane, O. (2008). Challenges facing teachers in the teaching of design and technology education in Botswana's primary schools. Design and Technology Education: An International Journal, 13(3), 9-18.

Rawagah, G. (1994). The Degree to Which PVE Course at Yarmouk University Satisfy the Training Needs of the Elementary School Teachers. Abhath Al-Yarmouk Journal, 10(3), 549-571.

Rohaan, E., Taconis, R. \& Jochems, W. (2010). Reviewing the relations between teachers' knowledge and pupils' attitude in the field of primary technology education. International Journal of Technology and Design Education, 20(1), 15-26.

Sherman, T., Sanders, M. \& Kwon, H. (2010). Teaching in middle school Technology Education: a review of recent practices. International Journal of Technology and Design Education, 20(4), 367-379.

Tsupros, N., Kohler, R. \& Hallinen, J. (2009). STEM education: A project to identify the missing components. A collaborative study conducted by the IU1 Center for STEM Education and 
$\begin{array}{llll}\text { Carnegie } & \text { Mellon } & \text { University. } & \text { Retrieved }\end{array}$ http://www.iu1stemcenter.org/files/PSTA_20308.pdf

Tweissi, A. (1999). Effectiveness and Efficiency of the Jordanian Prevocational Education Provision. Unpublished PhD Diss., Huddersfield University, UK.

Ugras, M. \& Cil, E. (2012). Procedia, Social and Behavioral Sciences, 47, 1545 - 1548.

Ulaimat, M. (1991). Pre-vocational education teaching methods. Irbid, Jordan: Dar Al-Malahi.

UNESCO. (1974). Revised Recommendation Concerning Technical and Vocational Education. General Conference of UNESCO, the 18th Session, Paris.

UNESCO. (2002). Technical and Vocational Education and Training for the Twenty-first Century: UNESCO and ILO Recommendations, UNESCO Publications.

Wafubwa, E. (2011). Teacher's perceptions towards the implementation of pre-vocational subjects in public primary schools in Bungoma Kunicipality, Kenya URI: http://erepository.uonbi.ac.ke:8080/handle/123456789/4414. 